\title{
Percepções de Graduandos de Psicologia Acerca do Trabalho do Psicólogo Escolar e Educacional
}

\author{
Elisa Alves dos Santos ${ }^{1}$ \\ ${ }^{1}$ Universidade Federal da Paraíba, PB, Brasil. \\ Nialda Sabrina da Silva ${ }^{1}$ \\ ${ }^{1}$ Universidade Federal da Paraíba, PB, Brasil.
}

\author{
Aline Rodrigues Gomes ${ }^{1}$ \\ ${ }^{1}$ Universidade Federal da Paraíba, PB, Brasil. \\ Fabíola de Sousa Braz Aquino ${ }^{1}$ \\ ${ }^{1}$ Universidade Federal da Paraíba, PB, Brasil.
}

Resumo: O objetivo desta pesquisa é apreender as percepções e expectativas de estudantes de graduação em psicologia acerca da psicologia escolar e das possibilidades de intervenção de psicólogos na educação. Participaram da pesquisa 48 graduandos de psicologia de instituições de ensino superior públicas e privadas. Foram aplicados um questionário sociodemográfico e uma entrevista semiestruturada que foi registrada por meio de um gravador de voz e posteriormente analisada conforme as diretrizes apresentadas no método de Bardin. Os resultados mostraram que houve diferenças nos argumentos utilizados entre os estudantes de psicologia que haviam cursado disciplinas do campo da psicologia escolar e Educacional e aqueles que ainda não haviam cursado tais disciplinas, o que indica que uma formação que contemple disciplinas desse campo pode favorecer uma maior apropriação teórica e metodológica acerca das especificidades dessa área e das possibilidades de atuação do psicólogo na educação, em especial, seu compromisso com processos de aprendizado e desenvolvimento humano.

Palavras-chave: Psicologia escolar, Formação, Graduandos.

\section{Perceptions of Undergraduate Psychology Students About Educational Psychologists' Work}

\begin{abstract}
This study records perceptions and expectations of psychology degree students about Scholar Psychology and the possibilities of psychologist actions in Education. The sample included 48 undergraduate Psychology students of Public and Private Higher Education Institutions. A socio-demographic questionnaire and a semi-structured interview recorded via voice recorder were applied then analyzed according to the guidelines presented in Bardin's method. The results showed that there were differences in arguments used among psychology students who had taken disciplines of Scholar and Educational Psychology field and those who had not yet studied such disciplines, which indicates that training including disciplines of this field can foster greater theoretical and methodological appropriation of particularities of this area and psychologists' possibilities of acting in education, especially regarding commitment to learning and human development processes.
\end{abstract}

Keywords: Scholar Psychology, Formation, Graduating Students. 


\title{
Percepción de Estudiantes de Graduación en Psicología acerca del Trabajo del Psicólogo Escolar y Educacional
}

\begin{abstract}
Resumen: El objetivo de esta investigación fue identificar las percepciones y expectativas de los estudiantes de graduación en Psicología acerca de la Psicología Escolar y de las posibilidades de intervención de psicólogos en la Educación. Participaron en el estudio 48 estudiantes de Psicología de Instituciones de Enseñanza Superior Públicas y Privadas. Se aplicó un cuestionario sociodemográfico y una entrevista semiestructurada, que se ha registrado por medio de una grabadora de voz para posteriormente evaluarla según las directrices presentadas en Bardin.Los resultados mostraron que hubo diferencias en los argumentos utilizados entre los estudiantes de psicología que habían cursado asignaturas del campo de la Psicología Escolar y Educacional y aquellos que aún no las habían cursado, lo que indica que una formación que contemple asignaturas de este campo puede favorecer una mayor apropiación teórica y metodológica acerca de las especificidades de esa área y de las posibilidades de actuación del psicólogo en la educación, sobre todo, en su compromiso con procesos de aprendizaje y desarrollo humano.
\end{abstract}

Palabras clave: Psicología Escolar, Formación, Estudiantes de Graduación.

\section{Introdução}

Esta pesquisa insere-se em um conjunto de estudos já realizados (Cavalcante \& Aquino, 2013) que demonstraram em seus resultados que as explicações e estratégias de intervenção de psicólogos escolares e docentes (Aquino et al., 2015) sobre as dificuldades das crianças em seu processo de escolarização, em contextos escolares públicos e privados, ainda se concentram no paradigma do "aluno-problema" e/ ou justificativas que recorrem às condições socioeconômicas de suas famílias. Essa compreensão tem gerado processos de exclusão social e escolar e, por conseguinte, não aprendizado por parte de crianças e jovens dos conhecimentos socioculturalmente construídos (Rego, 1995), já que os principais atores escolares afiguram-se desconhecer os mecanismos produtores desta problemática, o que se traduz pela negligência destes no enfrentamento das dificuldades no processo de escolarização dos alunos (Guzzo \& Mezzalira, 2011; Patto, 1997).

A presente pesquisa parte da ideia de que as formas de intervenção de psicólogos escolares e educacionais estão fortemente atreladas à formação disponibilizada pelos cursos de graduação em psicologia no país. As discussões em torno dessa questão foram iniciadas ao final da década de 1970 quando se passou a questionar para quem trabalhava e a quem servia o psicólogo escolar (Patto, 1997). A problematização em torno de ações remediativas e adaptacionistas implementadas nos primórdios da entrada de psicólogos nas escolas e ainda observadas nos dias atuais conduziu um debate intenso no interior da psicologia escolar e educacional entre as décadas de 1990 e 2000 no sentido de redimensionar e propor formas de atuação que denotassem um olhar mais crítico, ampliado e comprometido da psicologia com as demandas educacionais (Barbosa \& Marinho-Araujo, 2010; Borges-Andrade et al., 2015; Cavalcante \& Aquino, 2013; Maluf \& Cruces, 2008; Guzzo, 2002, 2008, 2011; Guzzo et al, 2009; MarinhoAraujo, 2005; Moreira \& Guzzo, 2016; Neves, 2011).

$\mathrm{Na}$ esteira desses debates surgem propostas de rediscussão da formação inicial nos cursos de graduação em psicologia objetivando construir "um perfil profissional comprometido com escolhas teórico críticas que atribuam sentido e significado a uma atuação político-social contextualizada" (Marinho-Araujo, 2009, p. 134), e um conjunto de propostas de intervenção pautadas na ideia de que o trabalho do psicólogo na escola reveste-se de especificidades e deve se concentrar em favorecer mediações intencionais nos vínculos entre os atores e a comunidade escolar. Conforme Antunes (2008), passou-se cada vez mais a reivindicar dos psicólogos uma atuação que se direcionasse para "a formação de professores, a intervenção no âmbito das relações escola-família-comunidade, e o processo grupal estabelecido na instituição 
escolar" (p. 473). De acordo com a autora, começava a ser forjado um movimento de crítica no interior da psicologia escolar e educacional orientado por uma ação do psicólogo efetivamente comprometido com o cotidiano da escola em sua função essencialmente pedagógica.

Discutindo a formação em psicologia para o campo da educação, Guzzo e Mezzalira (2011) referem-se à importância da formação de um novo perfil de psicólogo atento às possibilidades de mudança no processo educativo, um profissional que rompa com o determinismo e a alienação com que vem sendo tratado o processo de escolarização de crianças e jovens brasileiros. Por isso, pesquisadores como Meira (2003), defendem como um dos papéis do psicólogo escolar "a construção de um processo educacional qualitativamente superior" (p. 57) que permita a escola cumprir efetivamente seu papel de socialização de saber e de formação crítica. Para Guzzo (2003), "o psicólogo escolar trabalha em um sistema com o qual ele não tem familiaridade" (p. 28), o que se traduz em uma prática alienada que impossibilita mudanças na realidade e termina por afetar o aluno. Neste sentido, reafirma-se a importância de uma formação e embasamento teóricos amplos (Guzzo, 2003; Meira, 2003) que instrumentalizem o psicólogo a atender às demandas da comunidade escolar para além dos apelos em torno dos "alunos-problema" ou daqueles apontados por seus professores como apresentando dificuldades de aprendizagem.

Visando explorar a formação em psicologia para atuar no campo da educação, Silva (2017) realizou uma pesquisa que incluiu um levantamento acerca da formação e atuação do(a) psicólogo(a) para o campo da educação desde a graduação. Esse levantamento, realizado em bases de dados científicos e bancos de teses e dissertações, permitiu identificar estudos que concluíram que a efetivação das Diretrizes Curriculares para os Cursos de Graduação em psicologia (Brasil, 2004, 2011) favoreceu mudanças significativas em relação aos Projetos Político Pedagógicos dos Cursos (PPPC), que promovem uma formação mais ampla do profissional de psicologia, inclusive no que se refere à atuação do psicólogo escolar e educacional (Brasileiro \& Souza, 2010; Peretta et al., 2015, 2016). Por outro lado, estudos argumentam que a formação profissional em psicologia escolar e educacional não tem se constituído como prioritária para a formação do psicólogo, pois existe uma falta de identificação nos artigos relativa às especificidades da formação para atuar diretamente em psicologia escolar e educacional. Segundo afirmam, nesses artigos há apenas o reconhecimento da importância do impacto geral da formação na prática do psicólogo (Asbahr, 2014; Firbida \& Facci, 2015; Santos \& Toassa, 2015; Vieira et al., 2013).

Sobre essa questão, este estudo reafirma a importância de uma formação que possibilite ao estudante de psicologia um aprofundamento teórico-metodológico na área da psicologia escolar e educacional para que possa atuar de forma mais crítica, consciente e comprometida com a educação, o que pode colaborar para romper discursos cristalizados que ainda demonstram uma visão preconceituosa, fatalista e acrítica acerca do papel do psicólogo nos contextos educacionais (Guzzo, 2008; Marinho-Araujo, 2009; Martínez, 2010).

No que se refere à escolha por uma área de atuação em psicologia, concorda-se com Trigueiro (2015) que o acadêmico de psicologia ao ingressar no curso traz expectativas e ideias acerca da atuação do psicólogo, construídas pelas suas vivências com ela, pela representação desse profissional na mídia e sociedade. O conhecimento acerca da psicologia como ciência e profissão forma-se, e se desmistifica, a partir da inserção dos graduandos nos cursos.

Para ampliar e aprofundar as discussões e debate em torno da temática estudada, foi realizada uma revisão integrativa da literatura (Bianconi, 2013; Botelho et al., 2011; Costa et al., 2012; Ens \& Romanowski, 2006; Souza et al., 2010;) que partiu da base de dados BVS Psicologia. Em seguida realizou-se o levantamento das produções científicas nas seguintes bases de dados: Lilacs, SciELO, PePSIC, Medline e Portal de Periódicos Capes. Nesse levantamento foram incluídos artigos científicos nacionais publicados entre os anos de 2006 a 2016; publicações na área da psicologia escolar e educacional, e estudos que abordassem o tema das expectativas de graduandos de psicologia sobre a psicologia escolar e educacional. Os descritores utilizados foram: $p s i$ cologia escolar e concepções; psicologia escolar e formação; psicologia escolar, e graduação e psicologia escolar e expectativa.

A partir desse levantamento foram encontrados 494 artigos, distribuídos da seguinte forma: Lilacs (164); SciELO (183); PePSIC (25); Medline (7), e Portal de Periódicos Capes (115). Para a seleção de artigos 
relacionados aos objetivos do presente estudo, foi realizada a leitura dos títulos e resumos e, após esse procedimento, foram identificados apenas cinco artigos que foram lidos na íntegra para análise. Após esta leitura, foi verificado que apenas um artigo (Trigueiro, 2015) abordou a temática das expectativas de estudantes de psicologia sobre a psicologia escolar e educacional. Esse mesmo estudo pretendeu analisar a percepção de estudantes de psicologia de uma instituição de ensino superior privada sobre a psicologia escolar e educacional.

Os resultados desse estudo demonstraram que a concepção dos estudantes de psicologia sobre o trabalho do psicólogo escolar frente às questões educacionais denota uma visão individualizante e culpabilizante, que desconsidera os fatores sociais, históricos e culturais que perpassam o contexto escolar. Nesse estudo, verificou-se que a psicologia escolar e educacional ainda é uma das áreas menos escolhidas, visto que apenas $2,3 \%$ dos estudantes demonstram interesse em realizar formação nessa área. Ademais, foi verificado que os alunos de graduação que ainda não cursaram as disciplinas específicas da psicologia escolar e educacional demonstraram dificuldade e falta de conhecimento sobre essa área de atuação $(4,8 \%)$, expressas por respostas vagas, imprecisas ou inconsistentes, sobre a área.

Diante disso, ressalta-se a escassez de pesquisas realizadas no contexto brasileiro que busquem conhecer especificamente as percepções e expectativas de estudantes de psicologia acerca da psicologia escolar e educacional. Esse dado revela que essa temática vem sendo pouco estudada e discutida no âmbito acadêmico, justificando assim a importância do presente estudo. Ademais, defende-se nesta pesquisa que estudar tais percepções possibilita uma maior aproximação e conhecimento acerca dos motivos que podem sustentar a escolha ou não de acadêmicos de psicologia para atuar no campo da psicologia escolar e educacional, bem como para compreender quais aspectos da formação podem auxiliar na escolha (ou não) de trabalhar na área supracitada.

Compreendendo a estreita relação entre formação básica e as modalidades de atuação do profissional de psicologia no contexto escolar, o presente estudo objetiva apreender as concepções de estudantes de graduação em psicologia acerca da psicologia escolar e das possibilidades de intervenção de psicólogos no âmbito da educação. Especificamente, buscou-se listar os motivos que levaram os estudantes a ingressar no curso de psicologia; conhecer as expectativas dos estudantes dos primeiros períodos do curso de graduação em Psicologia em relação à psicologia escolar e educacional; aferir as principais percepções dos estudantes acerca da psicologia escolar e educacional; e relatar as principais funções do psicólogo escolar e educacional, segundo os graduandos de psicologia.

\section{Método}

\section{Materiais e técnicas de coleta de dados}

Para o processo de coleta de dados dos participantes foram aplicados um questionário sociodemográfico e uma entrevista semiestruturada registrada por meio de um gravador de voz (celular), lápis, papel e computador. O questionário sociodemográfico continha itens como idade, sexo, tipo de instituição (pública ou privada) e período do curso; e a entrevista semiestruturada continha oito questões, sendo adicionada uma nona questão para o grupo de estudantes que não haviam cursado as disciplinas específicas da psicologia escolar e educacional, buscando conhecer as expectativas deles acerca de tais disciplinas.

\section{Procedimentos éticos e de coleta de dados}

A pesquisa foi realizada de acordo com as normas da Resolução do Conselho Nacional de Saúde (CNS) no 510/2016, satisfazendo a legislação vigente, aprovada com o número CAAE 56815516.4.0000.5188. A participação dos graduandos na pesquisa foi realizada após a leitura e assinatura do Termo de Consentimento Livre e Esclarecido (TCLE).

\section{Participantes}

Participaram do presente estudo 48 graduandos, dos quais 35 são do sexo feminino, com faixa etária entre dezessete e 50 anos, e idade média de 22,3 anos. A amostra foi dividida em dois grupos distintos: o primeiro grupo (1), composto por 26 estudantes que não haviam cursado as disciplinas relacionadas à psicologia escolar e educacional, e grupo (2), composto por 22 estudantes que haviam cursado as disciplinas anteriormente citadas. Todos os participantes foram entrevistados na cidade de João Pessoa (Paraíba), em instituições de ensino superior (IES) pública e privada. 


\section{Procedimentos de análise dos dados}

O material obtido nas entrevistas foi analisado conforme as diretrizes da categorização de conteúdo apresentadas em Bardin (2008). Feito isso, realizou-se uma leitura flutuante e organizaram-se unidades gerais de análise e categorias a partir das falas dos estudantes entrevistados. É importante lembrar que os dados obtidos dessas entrevistas e suas posteriores categorias foram organizados de forma não excludente, portanto, uma mesma fala pode estar em mais de uma categoria. A análise do material obtido por meio das entrevistas foi seguida da discussão destas por um corpo de juízes formado por estudantes de graduação e de pós-graduação em psicologia que não tinham conhecimento do estudo. A composição do corpo de juízes deu-se visando discutir uma primeira categorização feita pelos pesquisadores do conteúdo das entrevistas, sua pertinência, concordância ou desacordo da categorização proposta. As respostas dos participantes foram organizadas em nove eixos de análise, que serão apresentados na próxima seção deste trabalho. Para melhor organização e garantia do sigilo, os participantes da pesquisa foram enumerados. Os resultados obtidos dessa análise são discutidos e analisados a partir de pesquisas do campo da psicologia escolar e educacional.

\section{Resultados e discussão}

\section{Motivos de graduandos para ingressarem no curso de psicologia}

O primeiro eixo de análise refere-se aos motivos que levaram os graduandos a ingressarem no curso de psicologia. Esse eixo derivou categorias, dentre as quais a mais citada foi motivos pessoais, exemplificada pelas seguintes falas: "a psicologia era a que mais me interessava e que eu achava que iria me adaptar melhor" (P2 - Grupo 1) e "estou aqui agora ainda por questões que aconteceram na vida e que me trouxeram pra cá e no caso eu vou terminar o curso" (P9-Grupo 2). A categoria conhecimento do ser humano refere-se às falas que se dirigiam à curiosidade em conhecer o ser humano e o que influencia em seu modo de pensar e se comportar, ilustrada por: "desde pequena eu gostei de observar as pessoas e de olhar o comportamento"; "oportunidade na psicologia de estudar o comportamento humano" (P10 - Grupo 2).
Também foram identificadas falas que permitiram a composição da categoria influência de pessoas. Essa categoria foi composta devido ao fato de os participantes relacionarem a escolha de cursar psicologia ao contato direto com um psicólogo ou de pessoas próximas, como pode ser ilustrada pela seguinte fala: "o pessoal dizia que eu era muito calma.... influência da minha psicóloga, da minha mãe, de amizades mesmo" (P2 - Grupo 1).

A categoria ajudar/cuidar do ser humano emergiu por meio das falas dos graduandos do Grupo 1 que mencionaram querer cuidar de pessoas e ajudá-las em momentos difíceis. Ilustra essa categoria a seguinte fala: "sempre foi meu forte cuidar das pessoas e então assim sempre tive é uma preocupação mais no âmbito da fragilidade, uma questão mais psíquica, uma questão mais teórica" (P7 - Grupo 1). De forma semelhante, o estudo realizado por Lins, Silva e Assis (2015) que investigou os motivos pelos quais os graduandos de psicologia optaram por este curso, revelou que treze dos 28 entrevistados tinham como objetivo inicial "ajudar as pessoas", o que pode representar um dos estereótipos compartilhados pelo senso comum quanto ao trabalho do profissional de psicologia. Ademais, quatro estudantes do Grupo 1 referiram pesquisas sobre as opções de profissão e, de todas, o curso de psicologia era aquele com o qual melhor se identificavam. Dentre esses, cita-se a seguinte fala: "comecei a pesquisar sobre o curso de psicologia e gostei e vi que era o que eu queria fazer" (P2 - Grupo 1).

A partir das falas do Grupo 2, emergiu a categoria abrangência do curso, que se refere à escolha do curso pela sua abrangência quanto ao públicoalvo (crianças, jovens, adultos, idosos) ou quanto às diversas áreas de atuação (saúde, trabalho, educação, entre outras), conforme pode ser observado na fala: "área bastante ampla... dá possibilidade da pessoa fazer diversos, diversos uso, e entrar em diversas áreas"(P14 - Grupo 2). Sobre esta categoria, o Conselho Federal de Psicologia (2007) mediante a Resolução 13/2007, no artigo $3^{\circ}$, ratifica as especialidades e possibilidades de atuação do(a) profissional de psicologia, apontando suas diversas possibilidades de contextos de trabalho. Além disso, as Diretrizes Curriculares Nacionais para os cursos de psicologia, promulgadas em 2004, determinam a estruturação dos cursos de forma que abarque diversas áreas. 
Os resultados mostram a diferença qualitativa nas falas dos participantes dos dois grupos quanto a suas justificativas para a escolha do curso de psicologia. Isso foi verificado em relação ao uso de termos mais técnicos na fala dos estudantes do Grupo 2, como pode ser visto na seguinte fala: "me identifiquei bastante com a proposta do trabalho psicológico" (P14 - Grupo 2). Esse excerto mostra o quanto o processo de formação influencia na linguagem utilizada pelos estudantes que já adquiriram embasamento teórico, fator primordial para a formação de um perfil e conduta como profissionais. Por isso, concorda-se com Marinho-Araújo (2009) e Antunes (2009, 2011) quanto à importância de a formação contemplar um perfil de psicólogo que esteja atento e comprometido com as demandas sociais e educacionais. Para pesquisadoras da área como Guzzo (2011), uma formação crítica possibilitará um novo perfil de formação em psicologia que rompa com a alienação dos profissionais que possuem uma postura determinista e individualizante. Tal postura não tem tido repercussão na sociedade, pois tem efeitos anestesiadores do verdadeiro potencial de um profissional que favoreça o desenvolvimento dos atores no processo de escolarização.

\section{Expectativas de graduandos de psicologia acerca das disciplinas de psicologia escolar educacional}

O segundo eixo de análise que emergiu das falas dos participantes do estudo foi expectativas dos estudantes acerca das disciplinas de psicologia escolar educacional. Sobre esse eixo, foi perguntado aos estudantes do Grupo 1 o que esperavam estudar nas disciplinas de psicologia escolar educacional. Acerca desta pergunta, o maior número de respostas refere-se a procedimentos, atuação elou conduta da(o) psicólo$g a(o)$, exemplificada a partir do seguinte relato: "como a gente deve aprender, ou, se comportar dentro de uma escola" (P3 - Grupo 1). Além dessa categoria, também emergiram da análise: intervenções direcionadas ao aluno (seis falas); obter conhecimento e embasamento teórico (seis falas); integração entre áreas da psicologia e/ou educação (quatro falas); relações institucionais (quatro falas); inserção na escola (três falas) e estudar dificuldades de aprendizagem (três falas).

Sobre essas categorias, estudos em psicologia escolar e educacional (Andrada, 2005; Facci \& Eidit,
2011; Neves, 2011; Patto, 1997) demonstraram que inicialmente o modo de atuação nesse campo era realizado de maneira reducionista e individualista, focando em atuações direcionadas aos alunos e a dificuldades atribuídas às crianças. A partir dos anos 2000, intensificaram-se estudos que ampliaram as leituras sobre o trabalho do psicólogo na educação, focando em análises sobre as queixas escolares e no processo de escolarização de crianças e adolescentes, e na proposição de modelos de atuação que considerem a multideterminação dos processos de ensino e aprendizagem (Barbosa \& Marinho-Araújo, 2010). Espera-se que, após cursarem as disciplinas da área, as concepções desses estudantes sejam modificadas e levem a uma reflexão sobre uma atuação que deve ser comprometida com os fatores socioeconômicos, políticos e históricos que atravessam a educação.

Além das categorias supracitadas, também foram mencionadas, de forma isolada, as seguintes categorias: estudar o contexto (familiar) da criança e como isso influencia na sua aprendizagem; desenvolver uma percepção crítica que venha revolucionar o sistema atual de ensino; questões de didática; dar atenção aos professores que lidam com alunos com deficiências.

\section{Concepções dos graduandos de psicologia acerca da psicologia escolar e educacional}

Além de se investigar os motivos que levaram à escolha pelo curso de psicologia e às expectativas dos graduandos de psicologia acerca da psicologia escolar e educacional, considerou-se pertinente conhecer as concepções dos graduandos acerca da psicologia escolar. Os resultados da análise dessa questão são apresentados na Tabela 1.

A Tabela 1 expõe as categorias originadas da análise das respostas dos participantes, a partir da pergunta: "Qual a sua compreensão acerca da psicologia escolar?”. As análises conduziram às seguintes categorias: atuar junto aos atores escolares, frequente na fala dos participantes que compõem os dois grupos, como se segue: "acho que a psicologia escolar éa atuação do psicólogo na escola junto com o pedagogo, junto com a coordenação da escola e com os alunos também" (P2 - Grupo 1) e "área que vai atuar diretamente com professores, gestores, coordenadores, com a família e com toda a comunidade ao qual ela tá inserida e não focar na questão da 'criança-problema"' (P14-Grupo 2). 
Tabela 1

Categorias relativas às concepções dos graduandos acerca da psicologia escolar e educacional.

\begin{tabular}{lcll}
\hline & $\begin{array}{c}\text { Grupo 1 } \\
(\mathrm{N}=26)\end{array}$ & $\begin{array}{c}\text { Grupo 2 } \\
(\mathrm{N}=22)\end{array}$ \\
\hline Atuar junto aos atores escolares & 8 & Atuar junto aos atores escolares & 8 \\
Pouca compreensão sobre a psicologia escolar & 7 & Área de atuação do psicólogo & 6 \\
Atuar nas escolas & 5 & Promover a educação e o aprendizado & 5 \\
Orientar os alunos & 5 & Atuar junto ao aluno & 4 \\
Atuar na promoção da educação e do aprendizado & 5 & Atua de forma ampla & 3 \\
Trabalhar com problemas de aprendizagem & 4 & Mediador & \\
Mediador & 3 & & \\
Trabalhar em conjunto com outras áreas/ & 3 & & \\
profissionais & & & \\
\hline
\end{tabular}

Sobre essa categoria, retomam-se as ideias de Souza (2009) e Guzzo e Mezzalira (2011), quando ressaltam a necessidade de o profissional desenvolver ações que envolvam todos os atores escolares, propiciando espaços que levantem discussões e promovam reflexões, de forma que todos participem integralmente. A atuação com todos os atores escolares é uma das dimensões proposta por Marinho-Araújo (2014), e que foi por ela chamada de assessoria ao trabalho coletivo, que consiste em uma ação realizada continuamente pelo profissional inserido no contexto da escola e totalmente imerso na instituição e comprometido com seu fazer.

Os estudantes que compõem o Grupo 1 falaram sobre ter pouca compreensão acerca da psicologia escolar, já que não haviam cursado as disciplinas da área. Tais estudantes direcionaram suas falas denotando uma compreensão de trabalho mais individualizado, como pode ser percebido pelas categorias orienta os alunos (cinco falas) e trabalha com problemas de aprendizagem (quatro falas). Faz-se necessário lembrar que tais ações são do âmbito do trabalho do psicólogo escolar, mas o profissional não se restringe a elas. Pesquisadores da área defendem ações integradas com os diversos setores da escola, as quais incluem os alunos (Guzzo, 2011; Marinho-Araújo, 2014; Neves, 2011; Souza et al., 2014).

Quatro categorias do grupo supracitado referem-se a ações que ocorrem na instituição, como: atuar nas escolas (cinco falas); atuar na promoção da educação e do aprendizado (cinco falas); atuar como mediador (três falas); e trabalhar em conjunto com outras áreas/profissionais (três falas). Esse contraste entre as duas primeiras categorias e as demais expressa as expectativas dos graduandos que não cursaram as disciplinas de psicologia escolar. Entende-se que os estudantes do curso de psicologia, ao ingressarem na graduação, trazem consigo representações cristalizadas sobre a atuação desse profissional na área da educação, visto que muitas vezes tem sido uma atuação distante dos problemas institucionais. Essa forma de atuação limita a repercussão na sociedade e, assim, acaba desfavorecendo a competência de um profissional que potencialize o desenvolvimento dos alunos (Guzzo, 2001).

Das seis categorias que emergiram a partir das falas dos participantes do Grupo 2, cinco são direcionadas a uma visão institucional. São elas: atuar junto aos atores escolares (oito falas); área de atuação do psicólogo (seis falas); promover a educação $e$ o aprendizado (cinco falas); e mediador (três falas). Menciona-se ainda a categoria atuar junto ao aluno (quatro falas), que se diferencia das demais.

\section{Percepções dos estudantes de psicologia sobre as questões, situações ou temas que deveriam ser alvo do trabalho do(a) psicólogo(a) escolar}

No que se refere à pergunta relativa às percepções dos estudantes sobre as questões, situações ou temas que deveriam ser alvo do trabalho do psicólogo escolar e educacional, os resultados das análises das entrevistas apontaram que, segundo o Grupo 1, os temas que deveriam ser trabalhados pelos psicólogos nas escolas seriam problemas de ordem individualizante (quatorze falas) tais como: conflitos; problemas pessoais; individualidade e subjetividade; o emocional do 
aluno; as dificuldades do aluno quanto a prestar atenção; a incapacidade e falta de habilidade do aluno; questões de comportamento, entre outros. Para exemplificar essa categoria, cita-se a seguinte fala: "entender a individualidade da criança e fazer com que a partir dessa individualidade, as questões que vão tá moldando ela na aprendizagem" (P6 - Grupo 1).

Para os estudantes do Grupo 2, os resultados da entrevista apontaram que a família (7 falas) é o tema mais recorrente. Nesta categoria, foram citados pelos participantes: o relacionamento entre a família; orientação e trabalho com os pais; questões familiares; família como ambiente social da criança. Como forma de melhor exemplificar, cita-se a seguinte fala: “. . . as questões familiares eu hoje consigo entender como uma questão fundamental pra o psicólogo escolar. Então assim, eu acho que o contexto individual é muito importante de ser explorado" (P9 - Grupo 2).

Os resultados do Grupo 1 e Grupo 2 apontam para a ideia de que o problema está ora na criança, ora na família, corroborando uma visão tradicional do contexto escolar e do que se entende como cerne de trabalho do psicólogo escolar e educacional. Por isso, concorda-se com Neves (2011) quando a autora estabelece como um dos níveis de atuação a família, mas no sentido de formar parceria para trabalhar a queixa escolar: a família é convocada para dar sua versão da queixa escolar, para elucidar questões relativas à história de escolarização dos estudantes. Enfatiza-se que na proposta de Neves (2011) o trabalho com a família ocorre após todas as possibilidades de trabalho no primeiro nível - a instituição - se exaurirem e tem como núcleo central buscar informações sobre o aluno com os docentes e a escola e sua relação com uma determinada queixa escolar.

Outras categorias de respostas à pergunta anteriormente citada se direcionaram nos dois grupos, para as formas de atuar nas relações, quer seja no favorecimento das relações (oito falas) do Grupo 1, como na mediação das relações entre os atores (seis falas) do Grupo 2. Tais categorias diferem qualitativamente, pois as falas dos graduandos que não haviam cursado as disciplinas se direcionam a mediar a relação do aluno frente aos outros atores escolares, portanto, o foco ainda parece estar no aluno. Em contrapartida, o outro grupo se refere ao trabalho com todos os atores escolares mediando as relações entre estes, tornando-se assim uma intervenção mais institucional. Diante disso, considera-se que a visão apresentada pelo Grupo 2 está mais próxima daquela defendida por Marinho-Araujo (2014). A autora enfatiza a importância de a psicologia escolar e educacional propor mediações intencionais em uma atuação institucional e coletiva que potencialize as relações sociais e proporcione o desenvolvimento psicológico tipicamente humano.

Outra categoria que emergiu a partir das falas dos graduandos e que se assemelhou nos dois grupos foi a promoção do processo de ensino-aprendizagem, com oito falas no Grupo 1 e seis no Grupo 2. Porém, os grupos se diferenciam qualitativamente, pois o Grupo 1 fala sobre uma aprendizagem que depende majoritariamente do professor, sem envolver todos os atores imbricados nessa relação, como pode-se observar em termos utilizados pelos estudantes, tais como: tornar o assunto mais atrativo, ajudar para que os alunos tenham uma aprendizagem melhor, entre outros. As respostas dos participantes do Grupo 2 demonstraram que todos os atores escolares contribuem no processo de ensino-aprendizagem, como pode ser observado na seguinte fala: "Acho que diretamente no processo de ensino-aprendizagem, porque o que a psicologia escolar vai fazer é isso, é focar dentro da instituição nesse processo, como se dá esse processo e como chega a ter esse processo de ensino-aprendizagem" (P14 - Grupo 2). Entende-se assim que a articulação da psicologia com a educação precisa ser feita por um profissional que efetive intervenções que privilegiem a promoção da aprendizagem e propiciem o desenvolvimento humano nos diversos contextos de educação formal e informal.

Ainda foram mencionados pelos graduandos como questões, situações ou temas que deveriam ser alvo do trabalho do psicólogo escolar e educacional, problemas de origem neurológica e cognitiva, tais como identificação do transtorno de déficit de atenção e hiperatividade (TDAH); déficit de aprendizagem; e a observação de comportamento do aluno, identificados em quatro falas dos graduandos do Grupo 1. Em contrapartida, as falas dos participantes do Grupo 2 se organizaram na categoria espaço institucional (cinco falas) como sendo o principal tema que deveria ser alvo do trabalho do psicólogo escolar e educacional, conforme a fala a seguir: "olhar institucional, tentando promover naquele lugar o desenvolvimento o mais produtivo possivel da criança. Não individualizando, sempre tentando trazer as questões para o coletivo" (P9 - Grupo 2). 
Sobre isso, Marinho-Araujo (2014) defende que o aluno precisa ser visto em sua totalidade e com todas as nuances que atravessam a sua vivência na instituição. Assim sendo, considera-se que a resposta do Grupo 1, focando no aluno de forma individual, não contempla o espaço escolar, pois "isola o indivíduo e sua subjetividade do mundo social e isenta as instituições” (Trigueiro, 2015, p. 227). Considera-se, portanto, que a visão do Grupo 2 é a mais aproximada do que se entende como alvo do trabalho do psicólogo escolar e educacional, pois sabe-se que as dificuldades encontradas nesse contexto são multideterminadas e necessitam ser vistas e trabalhadas dessa forma.

Ainda foram citados pelo Grupo 1 temas como bullying, conflitos sociais, questões econômicas, violência, drogas, gravidez na adolescência e trabalho infantil, com seis falas. No Grupo 2, ainda foram citados temas como evasão escolar, inclusão escolar, gênero e sexualidade, questões de drogas, violência, bullying, relações de preconceitos e potencializar as habilidades dos estudantes.

\section{Expectativas acerca dos contextos nos quais o psicólogo escolar e educacional pode atuar}

Já quando perguntados sobre os contextos nos quais o psicólogo escolar e educacional pode atuar, os graduandos do Grupo 1 citaram a escola como o principal contexto de atuação. Nesse grupo, quatro participantes mencionaram atividades como ensino e pesquisa. Outras respostas dos graduandos indicaram que houve uma interpretação distinta das anteriores à pergunta feita, e falaram sobre contextos de desenvolvimento e aprendizado, relações entre os atores escolares (professor-aluno, aluno-aluno, gestor-professor-aluno, entre outros), e contexto da família.

De forma semelhante, o Grupo 2 citou majoritariamente a escola como o principal contexto de atuação do psicólogo escolar e educacional, com onze falas. Além disso, foram citadas pelos graduandos desse grupo universidades e secretarias de educação, com três e quatro falas respectivamente; de forma isolada, foi citada a atuação em políticas públicas, creches; foi citada instituições que trabalham com educação, mas não de maneira formal, como o Centro de Apoio Psicossocial. Assim como os graduandos que não cursaram as disciplinas, respondentes desse grupo citaram a relação entre os atores escolares, desenvolvimento e aprendizado, família, entre outros.
Segundo Marinho-Araujo (2014), a escola é um importante campo de atuação do psicólogo escolar e educacional, atravessado por divergências e contradições, mas, de forma dialética, um espaço que pode favorecer transformação. No entanto, não é o único espaço, pois as possibilidades são variadas, tais como: educação básica, que inclui o ensino infantil (creches e pré-escolas), o ensino fundamental, e o ensino médio; a educação profissional técnica de nível médio; educação de jovens e adultos (EJA); educação profissional e tecnológica; educação superior; e a educação especial (Brasil, 1996). Ademais, as Diretrizes Curriculares Nacionais (2004) para os cursos de graduação em psicologia preconizam como objetivo dos cursos de graduação em psicologia "formar um profissional competente que, atuando eticamente, seja capaz de colaborar de forma criativa para o desenvolvimento da sociedade na qual está inserido." (2004, p. 5). Ressalta-se, portanto, o compromisso com uma atuação que considere as especificidades da área e do contexto no qual o profissional se insere.

\section{Percepções dos estudantes acerca das áreas ou campos de conhecimento da psicologia que dariam suporte teórico e metodológico para a atuação do psicólogo na educação}

Como parte desse estudo, foi perguntado aos participantes: "quais áreas ou campos de conhecimento da psicologia dariam suportes teóricos e metodológicos para a atuação do psicólogo na educação?”. Verificou-se, a partir da análise das respostas, a psicologia clínica como a mais citada pelos graduandos que não cursaram as disciplinas como a área que dá subsídios para a atuação em psicologia escolar e educacional, tal como se verifica na fala a seguir: "depende da teoria que esse psicólogo segue, como o psicanalista ele poderia ir tentar ajudar no contexto educacional do ponto de vista psicanalítico de como é a aprendizagem para a psicanálise" (P3 - Grupo 1). Sobre essa questão, ainda é presente nas escolas psicólogos fundamentados em um modelo clínico de atuação (Cavalcante, 2015; Cavalcante \& Aquino, 2013) que concentram suas intervenções na ideia de que os problemas de aprendizagem têm sua origem nas características dos alunos (Neves, 2007). A segunda mais manifestada foi a psicologia do desenvolvimento, como pode ser observado na seguinte fala: "Tipo, o contexto do desenvolvimento, do desenvolvimento infantil, vai trazer um 
acréscimo, entendeu, a isso" (P2 - Grupo 1). A categoria que melhor descreve o Grupo 1 aponta para ideias que muitas vezes os graduandos de psicologia, ao ingressarem no curso, trazem acerca da atuação do psicólogo, construídas pelas suas vivências com ela, pela representação desse profissional na mídia e na sociedade. Espera-se, porém, que após cursar as disciplinas específicas da área escolar, essa concepção modifique-se (Trigueiro, 2015).

Ainda sobre o Grupo 1, uma das áreas ou campos que mais emergiram nas respostas dos participantes foi a psicologia social, representada pela fala: "é, social. Eu acho que a social está em tudo" (P6 - Grupo 1). Seguida de psicologia da aprendizagem, representada pela seguinte fala: "as teorias $d a$ aprendizagem também” (P3 - Grupo 1). E, por último, a Comportamental, como pode ser vista na seguinte fala: "Eu acho que a do comportamento, né? A psicologia do comportamento também" (P2 - Grupo 1).

No grupo de respondentes que cursaram as disciplinas, a área ou campo de conhecimento mais citado foi a psicologia do desenvolvimento e para descrevê-la, cita-se a seguinte fala: "psicologia do desenvolvimento, entender a psicologia do desenvolvimento é fundamental" (P10 - Grupo 2). A segunda mais citada foi a psicologia da aprendizagem, como pode ser vista na seguinte fala: “. . . seria a questão da aprendizagem, de como o indivíduo aprende" (P12 - Grupo 2). Sobre as áreas ou campos de conhecimento da ciência psicológica que embasam a atuação do psicólogo na educação, Joly (2000) destaca aprendizagem e desenvolvimento humano como primordiais no processo de formação do psicólogo escolar, semelhante às respostas do Grupo 2.

\section{Percepções de graduandos de psicologia sobre as ações/intervenções do psicólogo escolar e educacional}

Como parte desse estudo também foram investigadas as percepções de graduandos de psicologia sobre as ações de um psicólogo escolar e educacional. Os resultados da análise dessa questão estão dispostos na Tabela 2.

A Tabela 2 expõe as categorias originadas da análise das respostas dos participantes a partir da pergunta "Para você, quais seriam as ações de um psicólogo escolar educacional?". A categoria mediar e/ou promover as relações entre os atores refere-se às respostas dos participantes do Grupo 1 e é exemplificada pela seguinte fala:

ajudar as pessoas na relação, para que seja uma coisa mais harmoniosa ajudar o professor no trabalho dele, tentar entender os alunos, passar o que os alunos precisam pra diretoria ajudar à diretoria passar o que eles precisam pros alunos (P3 - Grupo 1).

Tabela 2

Categorias relativas às percepções de graduandos de psicologia sobre as ações de um psicólogo escolar e educacional

\begin{tabular}{lclc}
\hline & $\begin{array}{c}\text { Grupo 1 } \\
\text { (N=26) }\end{array}$ & & $\begin{array}{c}\text { Grupo 2 } \\
(\mathrm{N}=22)\end{array}$ \\
\hline $\begin{array}{l}\text { Mediar e/ou Promover as relações } \\
\text { entre os atores }\end{array}$ & 9 & Dar assessoria ao trabalho coletivo & 9 \\
$\begin{array}{l}\text { Auxiliar os alunos com seus problemas } \\
\text { pessoais e/ou familiares }\end{array}$ & 5 & $\begin{array}{l}\text { Faz escuta psicológica das vozes } \\
\text { institucionais }\end{array}$ & 5 \\
Mediar conflitos & 3 & Realiza Mapeamento Institucional & 4 \\
& & $\begin{array}{l}\text { Conhece e/ou intervém visando o } \\
\text { alunado de forma individual e grupal }\end{array}$ & 3 \\
& Atua no Projeto Político Pedagógico & 3 \\
\hline
\end{tabular}


Além da categoria anteriormente citada, a partir das falas dos graduandos do Grupol, emergiram ainda as categorias auxiliar os alunos com seus problemas pessoais e/ou familiares (cinco falas) e mediar conflitos (três falas).

A primeira categoria se configura como uma das ações que um psicólogo escolar pode desenvolver no contexto escolar, e é corroborado por MarinhoAraujo (2014), quando ela fala sobre o papel do psicólogo como mediador nas mais variadas dimensões do desenvolvimento em contextos educacionais. Tendo isso em mente, as ações do profissional podem envolver os diversos atores institucionais e que estão em relação direta com o aluno. Em contrapartida, as duas últimas categorias se configuram em ações que ainda estão ancoradas em um modelo de atuação tradicional.

Os respondentes do Grupo 2 fizeram menções que denotaram ser o trabalho do psicólogo, assessoria ao trabalho coletivo, como exemplifica a seguinte fala: "atuar em reunião de professores e, também com os gestores... aprendi que a atuação diária deve ser essa atuação institucional, visando uma atuação completa no contexto escolar" (P16 - Grupo 2). Sobre essa categoria, Marinho-Araujo (2014) propõe que ela seja uma das ações do profissional e é colocada em prática junto ao corpo docente, à equipe técnica e direção, com o objetivo de proporcionar reflexão sobre práticas cristalizadas, conscientização e, assim, propiciar prováveis mudanças em concepções que orientam práticas pedagógicas como a noção do conceito de desenvolvimento, ensino e aprendizagem.

Ainda a respeito do Grupo 2, além da categoria supracitada, emergiram das análises das falas dos participantes desse grupo as categorias auxiliar os alunos com seus problemas pessoais elou familiares (cinco falas); realizar mapeamento institucional (quatro falas); conhecer elou intervir visando o alunado de forma individual e grupal (três falas); e atuar no Projeto Político Pedagógico (três falas). A primeira categoria considera, sobretudo, as características internas do aluno como determinantes da aprendizagem, além de colocar a família em um lugar que, ou propicie esse desenvolvimento "intrínseco", ou seja determinante para que não haja o desenvolvimento, apontando para uma concepção de atuação tradicional. As demais categorias sugerem uma atuação mais institucional, visando à coletividade e à influência de todos os atores no processo de ensino-aprendizagem (Marinho-Araujo, 2014). Destaca-se que os alunos que já haviam feito as disciplinas apresentaram uma compreensão ampliada do trabalho do psicólogo, citando mais possibilidades de atuação, com destaque às condutas focadas na instituição, relações entre os diversos grupos da escola e ao trabalho com os documentos que regem a instituição como o Projeto Político Pedagógico.

Quando questionados sobre se o trabalho do psicólogo escolar auxilia a escola e de que forma isso aconteceria, as respostas dos graduandos que não haviam cursado as disciplinas se concentraram em quatro categorias: ajudando a criançaladolescente (dificuldades, superação de problemas, aconselhamento); mediando as relações elou conflitos entre os atores escolares; intervindo nos problemas de aprendizagem; harmonizando o ambiente elou promovendo ações saudáveis. Para melhor exemplificar a primeira categoria citada, expõe-se a seguinte fala:

. . . Com certeza. O psicólogo eu acho que ele é uma ferramenta muito importante, porque ele vai ajudar a criança junto com o professor e os pais, no caso de ela ter algum problema que esteja afetando os estudos (P1 - Grupo 1).

Do grupo de graduandos que haviam cursado as disciplinas, as respostas à questão anteriormente citada se concentraram em três categorias: trabalhando de forma contextual com todos os atores escolares; facilitando o processo de ensino-aprendizagem; mediando as relações elou conflitos entre os atores escolares. Para ilustrar a primeira categoria, cita-se a seguinte fala: “. . . ele é o que dá suporte à atuação dos professores... nos gestores e no contexto que também envolve a família e o local que a escola está inserida, e os outros profissionais que trabalham na escola..." (P16 - Grupo 2).

É possível observar por meio dos resultados variações no conteúdo das respostas dos graduandos do Grupo 1 e do Grupo 2: aquele falou sobre ajudar a criança/adolescente e intervir nos problemas de aprendizagem; e este citou auxiliar e trabalhar de forma contextual com todos os atores escolares, facilitando o processo de ensino-aprendizagem. Isso pode demonstrar o impacto da formação que esses graduandos tiveram no curso de psicologia e a importância de uma formação que oportunize um aprofundamento teórico-metodológico na área da psicologia escolar e educacional. 


\section{Opinião dos estudantes de psicologia sobre se optariam pela área da psicologia escolar e educacional}

Os graduandos foram ainda perguntados sobre se optariam pela área da psicologia escolar e educacional e o porquê de suas respostas. Do grupo que ainda não havia cursado as disciplinas, as respostas se direcionaram para três categorias: não, tem outras preferências; sim, é uma das opções, uma possibilidade como outras áreas da psicologia. Cita-se a seguinte fala para melhor ilustrar a primeira categoria: “... eu acho que não, mas não por não considerar interessante, mas porque eu já tenho outras preferências..." (P3 - Grupo 1).

Quanto aos participantes que haviam cursado as disciplinas, quando perguntados sobre se optariam pela área, as respostas foram: não, por não se ver atuando; não é a prioridade; prefere a perspectiva clínica; não se identifica; sim. Para exemplificar as respostas que se direcionaram à forma negativa, cita-se a seguinte fala: "Não. Primeiro, porque eu não me identifico e não tenho vocação suficiente para atuar. E a questão financeira, de retorno financeiro, também é um fator que desmotiva" (P14 - Grupo 2).

Por outro lado, houve respostas que expressaram a possibilidade de atuação na área, como se segue: "é uma área que eu sou apaixonada, eu sou apaixonada pela área da educação, acredito que se você investe na educação, você investe em todo o resto do contexto geral" (P14 - Grupo 2).

$\mathrm{O}$ resultado à pergunta se optariam pela área da psicologia escolar e educacional mostrou que dos 48 estudantes questionados, dez estudantes $(20,8 \%)$ optariam pela área. Esse resultado, quando discutido à luz do estudo de Trigueiro (2015), pode indicar que conhecer o campo da psicologia escolar e educacional durante a graduação pode favorecer a adesão ao trabalho nessa área. Além disso, considera-se pertinente pontuar que as disposições das disciplinas ou componentes curriculares nos projetos político pedagógicos dos cursos de graduação em psicologia, as metodologias implementadas pelos docentes, bem como os referencias teóricos apresentados podem favorecer a inclinação de graduandos para o campo da psicologia escolar e educacional.

\section{Conclusão}

No presente estudo, buscou-se conhecer as concepções e expectativas dos graduandos de psicologia sobre a atuação do psicólogo escolar e educacional por considerar relevante investigar o que pensam esses graduandos sobre a atuação profissional de psicólogos na educação.

Os resultados mostraram que, de forma geral, os motivos que levaram os graduandos a optarem pelo curso de psicologia foram pessoais; que as expectativas acerca das disciplinas de psicologia escolar e educacional, para os graduandos de psicologia que não haviam cursado as disciplinas da área eram de que iriam estudar a atuação/conduta/ procedimentos do psicólogo dentro da escola. Identificou-se que a compreensão dos graduandos acerca da psicologia escolar e educacional é a de que o profissional atua junto aos atores escolares. No que tange à percepção dos estudantes quanto às questões, situações ou temas que devem ser alvo do trabalho do psicólogo na escola, verificou-se que, para o Grupo 1, os problemas de ordem individualizantes são os principais, e para o Grupo 2, a família é o principal problema.

Em relação aos contextos nos quais o psicólogo escolar e educacional atua, a escola foi o contexto majoritariamente citado. Para os participantes do estudo, os campos ou áreas de conhecimento da psicologia escolar e educacional que dão suporte teórico e metodológico para a atuação do psicólogo na educação, para o Grupo 1, é a psicologia clínica e a sua visão de homem; e, para o Grupo 2, a psicologia do desenvolvimento. No que concerne às percepções dos graduandos quanto às ações do psicólogo escolar e educacional, houve variações nos dois grupos, sendo que para o Grupo 1 a categoria que emergiu a partir das análises foi mediar e/ou promover as relações entre os atores e, para o Grupo 2, dar assessoria ao trabalho coletivo. Quando questionados em relação às possibilidades de o trabalho do psicólogo escolar e educacional auxiliar a escola e de que forma isso aconteceria, as análises mostraram que para o Grupo 1 esse profissional pode auxiliar ajudando a criança/adolescente; já para o Grupo 2, trabalhando de forma contextual com todos os atores escolares. Por último, quando perguntados se optariam pela área, apenas $20,8 \%$ responderam afirmativamente.

Os resultados permitem afirmar que a formação desde a graduação é de extrema importância para uma atuação que habilite o profissional para o contexto no qual irá atuar e que ele esteja comprometido com as necessidades e especificidades da área. Diante disso, pontua-se a relevância de uma formação que 
contemple em seu Projeto Político Pedagógico (PPP) disciplinas e atividades que possibilitem o aprofundamento na área da psicologia escolar e educacional, por meio das atividades de pesquisas e projetos de extensão, além de estágios supervisionados na área, permitindo assim uma maior apropriação teórica e metodológica das especificidades do campo.

Neste sentido, destaca-se a importância de as disciplinas de psicologia escolar e educacional serem incluídas no quadro de disciplinas obrigatórias de cursos de psicologia, colaborando para um maior aprofundamento na literatura que tem sido utilizado na área e permitindo a construção de um perfil que subsidie uma atuação neste campo. Destaca-se a necessidade de um PPP reestruturado que contemple as exigências das Diretrizes Curriculares Nacionais para os cursos de graduação em psicologia e demarque essa área como uma das ênfases desse curso.

O levantamento realizado no presente estudo permitiu observar que a produção de pesquisas acerca das percepções e expectativas dos graduandos de psicologia sobre a psicologia escolar e educacional tem sido pouco explorada, tendo em vista que apenas um artigo foi encontrado a respeito desse tema. Dessa forma, evidencia-se a necessidade de estudos que contemplem os aspectos aqui levantados e que demonstrem a relevância desse campo de atuação, principalmente no contexto local onde os psicólogos estão inseridos na Secretaria de Educação Municipal de João Pessoa, bem como em escolas públicas e privadas. Recomenda-se como estudos futuros ampliar os dados do presente estudo por meio de um levantamento em bases de dados internacionais e jornais específicos da área, materiais como livros e anais de congressos de congressos na área da psicologia e psicologia escolar e educacional, visando aprofundar os aspectos aqui explorados.

Como parte desse estudo, menciona-se como a principal dificuldade - a liberação por parte das instituições de ensino superior para realizar as entrevistas - e destaca-se, portanto, a relevância de as IES apoiarem a realização de pesquisas como essa, possibilitando conhecer o perfil dos estudantes que têm se formado no curso de psicologia e promover uma formação ampliada sobre as ações possíveis no campo da psicologia escolar e educacional.

Por fim, espera-se que o estudo aqui proposto fomente novas discussões sobre a formação nos cursos de graduação em psicologia e sua importância na construção de um perfil profissional que responda às demandas de contextos de educação, de forma ética, consciente, e comprometida socialmente.

\section{Referências}

Andrada, E. G. C. (2005). Novos paradigmas na prática do psicólogo escolar. Psicologia: Reflexão e Crítica, 18(2), 196-199. https://dx.doi.org/10.1590/S0102-79722005000200007

Antunes, M. A. M. (2008). Psicologia Escolar e Educacional: história, compromissos e perspectivas. Psicologia Escolar e Educacional, 12(2), 469-475. https://doi.org/10.1590/S1413-85572008000200020

Antunes, M. A. M. (2011). Psicologia e educação no Brasil: uma análise histórica. In R. G. Azzi \& M. H. T. Gianfaldoni (Orgs.), Psicologia e educação (pp. 9-32). São Paulo, SP: Casa do Psicólogo.

Aquino, F. S. B., Lins, R. P. S., Cavalcante, L. A., \& Gomes, A. R. (2015). Concepções e práticas de psicólogos escolares junto a docentes de escolas públicas. Associação Brasileira de Psicologia Escolar Educacional, 19(1), 71-78. https://dx.doi.org/10.1590/2175-3539/2015/0191799

Asbahr, F. S. F. (2014). Notas sobre o ensino de psicologia escolar em uma concepção crítica. Revista Psicologia: Ensino e Formação, 5, 20-31. http://pepsic.bvsalud.org/scielo.php?script=sci_arttext\&pi $\mathrm{d}=\mathrm{S} 2177-20612014000100003 \& \operatorname{lng}=\mathrm{pt} \& \operatorname{lng}=\mathrm{pt}$.

Barbosa, R. M. \& Marinho-Araujo, C. M. (2010). Psicologia escolar no Brasil: considerações e reflexões históricas. Estudos de Psicologia, 27(3), 393-402.

Bardin, L. (2008). Análise de conteúdo. Lisboa: Edições 70.

Bianconi, R. (2013). Produção científica sobre políticas de educação superior no Brasil para a modalidade a distância - 2003 a 2010 (Dissertação de mestrado). Universidade Católica Dom Bosco, Campo Grande, MS.

Borges-Andrade, J. E., Bastos, A. V. B., Andery, M. A. P. A., Guzzo, R. S. L, \& Trindade, Z. A. (2015). Psicologia brasileira: uma análise de seu desenvolvimento. Universitas Psychologica, 14(3). http://dx.doi.org/10.11144/ Javeriana.upsy14-3.pbua 
Botelho L. L. R., Cunha C. C. A., \& Macedo M. (2011). O método da revisão integrativa nos estudos organizacionais. Gestão e Sociedade, 5(11), 121-36. http://dx.doi.org/10.21171/ges.v5i11.1220

Brasil. (2004). Parecer 0062/2004 de 19 de fevereiro de 2004. Fixa as Diretrizes Curriculares Nacionais para os cursos de graduação em Psicologia. Brasília, DF: Ministério da Educação.

Brasil. (2011). Resolução no 5, de 15 de março de 2011. Conselho Nacional de Educação. Diário Oficial da União, Brasília, DF.

Brasileiro, T. S. A., \& Souza, M. P. R. (2010). Psicologia, diretrizes curriculares e processos educativos na Amazônia: um estudo da formação de psicólogos. Psicologia Escolar e Educacional,14(1), 105-120.

Cavalcante, L. A. (2015). O psicólogo na rede pública de educação: concepções, formação e atuação profissional (Dissertação de mestrado). Universidade Federal da Paraíba, João Pessoa, PB.

Cavalcante, L. A., \& Aquino, F. S. (2013). Ações de psicólogos escolares de João Pessoa sobre queixas escolares. Psicologia em Estudo, 18, 353-362. https://dx.doi.org/10.1590/S1413-73722013000200016

Conselho Federal de Psicologia. (2007). Resolução CFP no 013/2007. Institui a Consolidação das Resoluções relativas ao Título Profissional de Especialista em Psicologia e dispõe sobre normas e procedimentos para seu registro. Brasília, DF.

Costa, J. P., Amorim, K. M. O., Pessanha, V. C., \& Yamamoto, O. H. (2012). Quem estuda a profissão de psicólogo no Brasil? Arquivos Brasileiros de Psicologia, 64(2), 2-18. http://pepsic.bvsalud.org/scielo.php?script=sci_ arttext\&pid=S1809-52672012000200002\&lng=pt\&tlng=pt

Ens, R., \& Romanowski, J. P. T. (2006). As pesquisas denominadas do tipo "estado da arte" em educação. Revista Diálogo Educacional, 6(19), 37-50. http://www2.pucpr.br/reol/pb/index.php/dialogo?ddl=237\&dd99=view

Facci, M. G. D., \& Eidit, N. M. (2011). Formação do psicólogo para atuar na instituição de ensino: a queixa escolar em questão. In R. G. Azzi \& M. H. T. Gianfaldoni (Org.), Psicologia e Educação (Vol. 1, pp. 129-153). São Paulo, SP: Casa do Psicólogo.

Firbida, B. G. F., \&Facci, G. D. M. (2015). A formação do psicólogo no estado do Paraná para atuar na escola. Revista: Psicologia Escolar e Educacional, 19(1), 173-184. https://dx.doi.org/10.1590/2175-3539/2015/0191817

Guzzo, R. S. L. (2001). Formando psicólogos escolares no Brasil, dificuldades e perspectivas. In S. M. Wechsler (Org.), Psicologia escolar: pesquisa, formação e prática (2a ed., pp. 75-92). Campinas, SP: Alínea.

Guzzo, R. S. L. (2002). Novo paradigma para a formação e atuação do psicólogo escolar no cenário educacional brasileiro. In R. S. L. Guzzo (Org.), Psicologia escolar: LDB e educação hoje (pp. 131-144). Campinas, SP: Alínea.

Guzzo, R. S. L. (2003). Saúde psicológica, sucesso escolar e eficácia da escola: desafios do novo milênio para a psicologia escolar. Em: Z. A., P; Del, Prette (Org.), Psicologia escolar e educacional, saúde e qualidade de vida: explorando fronteiras (pp. 25-42). Campinas: Alínea.

Guzzo, R. S. L. (2008). Psicologia em instituições escolares e educativas: apontamentos para um debate. In Conselho Federal de Psicologia, Conselhos Regionais de Psicologia (Org.), Ano da psicologia na educação: textos geradores (pp. 53-61). Brasília, DF: Brasília Rádio Center.

Guzzo, R. S. L. (2011). Formando psicólogos escolares no Brasil: dificuldades e perspectivas. In S.M. Wechsler (Org.), Psicologia escolar: pesquisa, formação e prática (4a ed., pp. 63-79). Campinas, SP: Alínea.

Guzzo, R. S. L., Costa, A. S., \& Sant'ana I. M. (2009). Formando psicólogos escolares: problemas, vulnerabilidades, desafios e horizontes. In C. M. Marinho-Araujo (Org.), Psicologia escolar: novos cenários e contextos de pesquisa, prática e formação (pp. 35-52). Campinas, SP: Alínea.

Guzzo, R. S. L., \& Mezzalira, A. S. C. (2011). 2008, Ano da Educação para os Psicólogos: encaminhamentos e próximos passos. In R. S. L. Guzzo \& C. M. Marinho-Araujo (Orgs.), Psicologia Escolar: identificando e superando barreiras (pp. 11-31). Campinas, SP: Alínea.

Joly, M. C. R. A. (2000). A formação do psicólogo escolar e a educação no terceiro milênio. Psicologia Escolar Educacional, 4(2), 51-55. https://dx.doi.org/10.1590/S1413-85572000000200006 
Lins, L. F. T., Silva, L. G., \& Assis, C. L. (2015). Formação em psicologia: perfil e expectativas de concluintes do interior do estado de Rondônia. Gerais: Revista Interinstitucional de Psicologia, 8(1), 49-62. http://pepsic. bvsalud.org/scielo.php?script=sci_arttext\&pid=S1983-82202015000100005\&lng=pt

Maluf, M. R.; Cruces, A. V. V. (2008). Psicologia educacional na contemporaneidade. Boletim - Academia Paulista de Psicologia, 28(1), 87-99.

Marinho-Araujo, C. M. (2005). Psicologia e o desenvolvimento de competências. Boletim Academia Paulista de Psicologia, 25(2-5), 73-85. http:/ / www.redalyc.org/articulo.oa?id=94625212

Marinho-Araujo, C. M. (2009). Psicologia escolar na educação superior: novos cenários de intervenção e pesquisa. In C. M. Marinho-Araujo (Org.), Psicologia escolar: novos cenários e contextos de pesquisa, formação e prática (Vol. 1, pp. 133-174). Campinas, SP: Grupo Átomo e Alínea.

Marinho-Araujo, C. M. (2014). Intervenção institucional: ampliação crítica e políticas da atuação em Psicologia Escolar. In R. S. L. Guzzo (Org.), Psicologia escolar: desafios e bastidores da escola pública (pp. 153-176). Campinas, SP: Alínea.

Martínez, A. M. (2010). O que pode fazer o psicólogo na escola? Em Aberto, 23(83), 39-56. http://dx.doi.org/ 10.24109/2176-6673.emaberto.23i83.\%25p

Meira, M. E. M. (2003). Construindo uma concepção de psicologia escolar: contribuições da pedagogia histórico-crítica e da psicologia sócio-histórica. In M. E. M. Meira \& M. A. M. Antunes (Orgs.), Psicologia escolar: teorias críticas (pp. 13-78). São Paulo, SP: Casa do Psicólogo.

Moreira, A. P. G., \& Guzzo, R. S. L. (2016). Situação-limite e potência de ação: Atuação preventiva crítica em psicologia escolar. Estudos de Psicologia (Natal), 21(2), 204-215. https://doi.org/10.5935/1678-4669.20160020

Neves, M. M. B. J. (2007). Formação inicial em psicologia escolar: questões apontadas por alunos de graduação. In H. R. Campos (Org.), Formação em psicologia escolar: realidades e perspectivas (2a ed., pp. 49-67). Campinas, SP: Alínea.

Neves, M. M. B. J. (2011). Queixas escolares: conceituação, discussão e modelo de atuação. In C. M. MarinhoAraujo (Org.), Psicologia escolar: identificando e superando barreiras (pp. 175-214). Campinas, SP: Átomo e Alínea.

Patto, M. H. S. (Org.). (1997). Introdução à psicologia escolar. São Paulo, SP: Casa do Psicólogo.

Peretta, A. A. C. S., Silva, S. M. C., Naves, F. F., Nasciutti, F. M. B., \& Silva, L. S. (2015). Novas diretrizes em tempos desafiadores: formação em psicologia para atuar na Educação. Revista Quadrimestral da Associação Brasileira de Psicologia Escolar e Educacional, 19(3), 547-556. https://dx.doi.org/10.1590/2175-3539/2015/0193893

Peretta, A. A. C. S., Silva, S. M. C., Naves, F. F., Nasciutti, F. M. B., Silva, L. S., \& Lima, N. P. (2016). Formação do psicólogo para atuar na educação: concepções de coordenadores de curso. Revista Psicologia: Ciência e Profissão, 36(1), 48-62. https://dx.doi.org/10.1590/2175-3539/2015/0193893

Rego, T. C. (1995). Vygotsky: uma perspectiva histórico-cultural da educação (4a ed.). Petrópolis, RJ: Vozes.

Santos, F. O., \& Toassa, G. (2015). A formação de psicólogos escolares no Brasil: uma revisão bibliográfica. Revista Quadrimestral da Associação Brasileira de Psicologia Escolar e Educacional, 19(2), 279-288. http://dx.doi.org/10.1590/2175-3539/2015/0192836

Souza, M. P. R. (2009). Psicologia escolar e educacional em busca de novas perspectivas. Psicologia Escolar $e$ Educacional, 13(1), 179-182. https://dx.doi.org/10.1590/S1413-85572009000100021

Souza, M. T., Silva, M. D., \& Carvalho, R. (2010). Revisão integrativa: o que é e como fazer. Einstein, 8(1), 102106. https://dx.doi.org/10.1590/s1679-45082010rw1134

Silva, N. S. (2017). Um estudo de levantamento nos cursos de graduação em Psicologia no âmbito da Psicologia na Educação (Relatório Final Pibic). Universidade Federal da Paraíba, João Pessoa, PB.

Trigueiro, E. S. O. (2015). A psicologia escolar e o estudante de psicologia: elementos para o debate. Psicologia Escolar e Educacional, 19(2), 223-232. https://dx.doi.org/10.1590/2175-3539/2015/0192820

Vieira, R. C., Figueiredo, E. R., Souza, L. G., \& Fenner, M. C. (2013). A psicologia da educação nos cursos de graduação em psicologia de Belo Horizonte/MG. Revista: Psicologia Escolar Educacional, 17(2), 239-248. https://dx.doi.org/10.1590/S1413-85572013000200006 


\section{Elisa Alves dos Santos}

Psicóloga pela Universidade Federal da Paraíba (UFPB). Membro do Núcleo de Estudos em Interação Social e Desenvolvimento Infantil (Neisdi), João Pessoa - PB. Brasil.

E-mail: elisa.alves1994@gmail.com

(iD) https://orcid.org/0000-0001-6517-8502

Nialda Sabrina da Silva

Psicóloga pela Universidade Federal da Paraíba (UFPB). Membro do Núcleo de Estudos em Interação Social e Desenvolvimento Infantil (Neisdi), João Pessoa - PB. Brasil.

E-mail: nialdasabrina@hotmail.com

(D) https://orcid.org/0000-0001-5399-6583

\section{Aline Rodrigues Gomes}

Psicóloga Escolar. Mestreem PsicologiaSocial pelo Programa dePós-Graduação em Psicologia Socialda Universidade Federal da Paraíba (PPgPS/UFPB). Membro do Núcleo de Estudos em Interação Social e Desenvolvimento Infantil (Neisdi), João Pessoa - PB. Brasil.

E-mail: alinegomesr@gmail.com

(D) https://orcid.org/0000-0003-4686-304X

\section{Fabíola de Sousa Braz Aquino}

Professora Associada do Departamento de Psicologia e do Programa de Pós-Graduação em Psicologia Social da Universidade Federal da Paraíba. Pesquisadora do Núcleo de Estudos em Interação social e Desenvolvimento Infantil (Neisdi). Membro do GT de Psicologia Escolar e Educacional da Anpepp, João Pessoa - PB. Brasil.

E-mail: fabiolabrazaquino@gmail.com

(D) https://orcid.org/0000-0002-8854-8577

Agradecemos ao CNPq pelo financiamento de pesquisa de Iniciação Científica que derivou este artigo.

Endereço para envio de correspondência:

Rua Carmem Coeli Cantalice Moreira, 169, Mangabeira IV. CEP: 58057-455. João Pessoa - PB. Brasil.

Recebido $26 / 12 / 2017$

Aceito 07/08/2018

Received 26/12/2017

Approved 07/08/2018

Recibido 26/12/2017

Aceptado 07/08/2018

Como citar: Santos, E. A., Silva, N. S., Gomes, A. R., \& Braz Aquino, F. S. (2020). Percepções de Graduandos de Psicologia Acerca do Trabalho do Psicólogo Escolar e Educacional. Psicologia: Ciência e Profissão, 40, 1-16. https://doi.org/10.1590/1982-3703003189579

How to cite: Santos, E. A., Silva, N. S., Gomes, A. R., \& Braz Aquino, F. S. (2020). Perceptions of Undergraduate Psychology Students About Educational Psychologists' Work. Psicologia: Ciência e Profissão, 40, 1-16. https://doi.org/10.1590/1982-3703003189579

Cómo citar: Santos, E. A., Silva, N. S., Gomes, A. R., \& Braz Aquino, F. S. (2020). Percepción de Estudiantes de Graduación en Psicología acerca del Trabajo del Psicólogo Escolar y Educacional. Psicologia: Ciência e Profissão, 40, 1-16. https:// doi.org/10.1590/1982-3703003189579 